\title{
SEISMIC PERFORMANCE OF EXTERNAL REINFORCED CONCRETE BEAM-COLUMN JOINTS
}

\author{
Les Megget ${ }^{1}$ and Richard Fenwick ${ }^{2}$
}

\begin{abstract}
Four external beam-column sub-assemblies were tested to investigate the influence of different details on the performance of the joint zone. All the details conformed to the current New Zealand structural concrete standard (NZS3101-1995). It is shown that anchoring beam reinforcement in external beamcolumn joints short of the outer column bars results in a reduction in the flexural strength of the column. In tests premature yielding of the longitudinal bars on the inside of the column occurred when bars were anchored at a distance of $1 / 4$ of the column depth from the outside face of the column, as permitted by the structural concrete Standard. This yielding had an adverse effect on the performance of the joint zone. A way of detailing external joint zones to compensate for this loss in strength is described. Elongation of plastic hinges in the beams of ductile frames induces unidirectional plastic hinges in the external columns at the first floor level. While this has a strong influence on the distribution of moments and shears in the columns tests indicated that it does not adversely affect the structural performance of the joint zone. The use of continuous bars bent in the form of a $U$ provides a simple detail that worked very effectively. There was little difference in joint behaviour between beams with main bars uniformly distributed over the beam depth to conventionally reinforced beams with their main bars positioned near the top and bottom edges.
\end{abstract}

\section{INTRODUCTION}

This paper describes the cyclic load testing of 4 external reinforced beam-column joint sub-assemblies. The objectives of these tests were to;

(a) Assess the influence of terminating beam bars in joint zones short of the external column bars, as permitted by the current structural concrete standard (NZS31011995);

(b) Examine the influence of beam elongation, due to plastic hinging, on the performance of beam-column joint zones at the level of the first floor beams in multistorey frames;

(c) Examine the influence of different forms of beam bar anchorage in joint zones on the performance of the joint zones;

(d) Compare the relative performance of joint zones between beams and columns where the beams are reinforced with uniformly distributed reinforcement over the depth of the member, and joint zones where the beams contain longitudinal reinforcement concentrated at the top and bottom of the member.

The current New Zealand Structural Standard [1] is very specific about the detailing of beam bars within external beam-column joints of ductile reinforced concrete frames. Where a potential plastic hinge zone is located in the beam at the face of the column, longitudinal beam bars must be anchored by a standard hook a distance from the inside face of the column of no less than $3 / 4$ of the column depth. The first 3 beam-column joint sub-assemblies described in this paper had this detail (see Figure 1) so that the significance of anchoring the bars short of external longitudinal reinforcement in the column could be established. In the fourth sub-assembly the longitudinal reinforcement in the beam consisted of $7 \mathrm{U}$ shaped bars, which were distributed uniformly over the depth of the beam. Each bar was in a horizontal plane and they were anchored as close as possible to the outside edge of the column face.

Previous research on the seismic behaviour of ductile frames [2] found plastic hinge zones elongate by between 2 and 3 percent of the beam's depth when design ductility levels are reached. When the columns of multi-storey frames are fixed into non-yielding foundations at ground level, the elongation of the beams at the higher levels causes the external columns to be bent outwards as is illustrated in Figure 2. Both analytical and experimental work has shown that this deformation may be expected to occur in major earthquakes $[3,4]$. This elongation imposes a displacement on the column, which induces axial compression in the beam and a unidirectional plastic hinge in the column close to the first floor beams. The magnitude of the axial compression force in the beam depends on the strength of the column in flexure. The formation of the unidirectional plastic hinge occurs even though the normal "weak beam-strong column" capacity design approach has been followed in the design and detailing.

The second beam-column joint subassembly described in this paper had the free end of the beam restrained so that it could not move laterally in the plane of the frame. In this unit the beam plastic hinge generated an axial load that forced a unidirectional plastic hinge to form in the column, in a similar manner to that observed in analyses and tests [3]. Hence it modelled the situation described in the previous paragraph.

The 1995 NZ Concrete Standard [1], when compared with the previous 1982 edition, allowed a considerable reduction in the amount of horizontal and vertical reinforcement

\footnotetext{
'Department of Civil \& Environmental Engineering, University of Auckland, (Fellow)

'Recently retired from Dept. of Civil \& Environmental Engineering, University of Auckland, (Life Member).
} 
required in external beam-column joints. However, there was only limited testing evidence for this reduction. The beam-column subassemblies described in this paper complied with the current 1995 Standard in all aspects except one. In the first two units the anti-buckling ties required to hold the central 4 column bars in place were omitted. These were added for units 3 and 4 . However, as no axial load was applied to the columns in these units it is believed that this omission had little influence on the performance of the first two test units.

\section{DETAILS OF TEST UNITS}

All four beam-column joints had identical beam and column sizes. The beams were 515 deep by $250 \mathrm{~mm}$ wide and the columns were $500 \mathrm{~mm}$ deep by $300 \mathrm{~mm}$ wide. The units were approximately $2 / 3$ of full scale with $2,250 \mathrm{~mm}$ long beams measured from column centreline to point of load application (assumed mid-span) with an inter-storey height of $2,250 \mathrm{~mm}$. Figure 1 shows the unit dimensions and the reinforcing details used for the beam-column sub-assemblies. The test specimens were cast on their sides and put into a vertical position for testing. Ready mix concrete with a specified 28-day strength of $25 \mathrm{MPa}$ (expected strength of 30 $\mathrm{MPa}$ ) was used in all units. The actual cylinder tests gave compressive strengths of 46.7 and $48 \mathrm{MPa}$ for units 1 and 2, respectively and $33.9 \mathrm{MPa}$ for units 3 and 4 . The cover measured to the longitudinal bars was maintained at $30 \mathrm{~mm}$ for all the units.

The first two beam-column sub-assemblies, units 1 and 2 , were "conventional" with equal top and bottom bars (4D20H with a yield stress, $f_{y}$, of $452 \mathrm{MPa}$ ). These bars had standard hook anchorage within the joint zone (90-degree inward bends with $12 \mathrm{~d}_{\mathrm{h}}$ tails). The outer faces of the bottom beam bars were positioned at exactly $1 / 4$ of the column depth $(125 \mathrm{~mm})$ from the column's outer face. The top bars were placed outwardly adjacent to the bottom bars as shown in Figure 1. The column bars were $12-\mathrm{D} 16$ bars $\left(\mathrm{f}_{\mathrm{y}}\right.$ of 326 $\mathrm{MPa}$ ). The horizontal joint zone ties comprised 4 sets of 4 leg R10 ties $\left(\mathrm{f}_{\mathrm{yh}}\right.$ of $\left.318 \mathrm{MPa}\right)$. All ties were anchored with 135-degree bends with $8 \mathrm{~d}_{\mathrm{b}}$ tails, as specified in the Standard [1]. In the beam R6 and R8 rectangular ties were used at 115 $\mathrm{mm}$ centre to centre. The details are shown on the Figure 1.

The third sub-assembly, unit 3, was very similar to the earlier joints except the 4-D20H beam bars were continuous U-bars ( $f_{y}$ of $482 \mathrm{MPa}$ ), which were placed to give a clear gap of 125 $\mathrm{mm}$ from the outer column face. The beam ties were changed to double R6 tie-sets at $90 \mathrm{~mm} \mathrm{c} / \mathrm{c}$ as shown in Fig. 1. This change was made as $8 \mathrm{~mm}$ bars were no longer available. To reduce the loss in flexural strength observed in the first test, which was associated with anchoring the beam bars in the joint zone short of the longitudinal column reinforcement (see Fig. 3), the inner 4-D16 column bars were replaced with 4-D20 bars ( $f_{y}$ of $334 \mathrm{MPa}$ ). The column ties consisted of sets of three R6 ties placed at $90 \mathrm{~mm}$ centre to centre. In the joint zone four sets of ties were used. Each set consisted of a perimeter R10 ties with two internal R6 ties.

In the last sub-assembly, unit 4 , the beam longitudinal reinforcement consisted of $7 \mathrm{D} 16 \mathrm{H} \mathrm{U}$-bars $\left(\mathrm{f}_{\mathrm{y}}\right.$ of $465 \mathrm{MPa}$ ) placed at $72.5 \mathrm{~mm}$ centres vertically, to give a uniform distribution of reinforcement over the depth of the beam. Two vertical D16H bars, $520 \mathrm{~mm}$ long, were positioned in each corner of the $\mathrm{U}$ bars to improve their anchorage in the joint zone. In this unit the beam ties were single R6 stirrups at $50 \mathrm{~mm} \mathrm{c} / \mathrm{c}$. The reduced spacing arose as ties with 2 legs were used instead of the sets of 4 leg ties that were used in the previous units. The column and joint transverse ties were identical to those in unit 3 .

Based on a 1.15 factor for strain hardening the design shear stress in the joint zone for units 1 and 2 was $3.34 \mathrm{MPa}$ $(0.49 \sqrt{f}$, and $0.48 \sqrt{f}$, , respectively), while in units 3 and 4 it was $3.62 \mathrm{MPa}(0.62 \sqrt{f})$ and $3.98 \mathrm{MPa}$ $(0.68 \sqrt{f})$, respectively. In unit 4 the joint shear stress was calculated at mid-depth assuming that 7-D16 beam bars were yielding. These joint shear stresses are well below the maximum permitted value of $0.2 f_{\mathrm{c}}{ }^{\prime}(9.4 \mathrm{MPa}$ for the units 1 and 2 and $6.8 \mathrm{MPa}$ for units 3 and 4 ).

All the units were tested with a vertical cyclic force applied by hydraulic jack positioned 2 metres out from the column face. This force supplied the simulated seismic moments and shears to the units. In unit 2 another jack was positioned to apply a horizontal force to the free end of the beam, as shown in Figure 1. During the test the force in this jack was adjusted to keep the mid-depth point at the end of the beam on the same vertical line. With this arrangement any elongation in the beam resulted in an axial force being applied to the beam, which transferred it to the column, bending this member as illustrated in Figure 2. This modelled the condition acting at the first elevated level in a two-bay frame.

The design flexural overstrength of the beams was taken as 1.15 times the nominal strength. This factor allowed for the expected increase in strength due to strain hardening of the reinforcement. The Standard indicates that for Grade 430 reinforcement the overstrength bending moment should be taken as 1.25 times the nominal value. However, this coefficient incorporates an allowance for the difference in actual yield strength to the design value (lower characteristic strength), which is inappropriate in this situation, as the actual values were known and used in determining the theoretical strengths. These values are given in Table 1 . The values for the column sections have been calculated assuming the axial load associated with the predicted beam overstrength moment acts. It should be noted the axial load is different in the top and bottom columns and that in units 3 and 4 different reinforcement arrangements are used on the inside and outside faces of the column. Consequently there are two flexural strengths for these columns depending on which side is in tension. The last column in the Table gives the ratio of the theoretical nominal column strength to the beam strength. It can be seen that these values range between 1.32 and 1.48. For unit 2 a single value cannot be calculated as this varies with the axial load in the beam.

With spread reinforcement in the columns the actions sustained at first yield are significantly smaller than the theoretical ultimate strengths. First yield in the column occurs at about $75 \%$ of the theoretical strength. To sustain the beam overstrength bending moment of $290 \mathrm{kNm}$ the theoretical strain in the column reinforcement next to the inside face of the column reaches a value of about 1.8 times the bar's yield strain. 


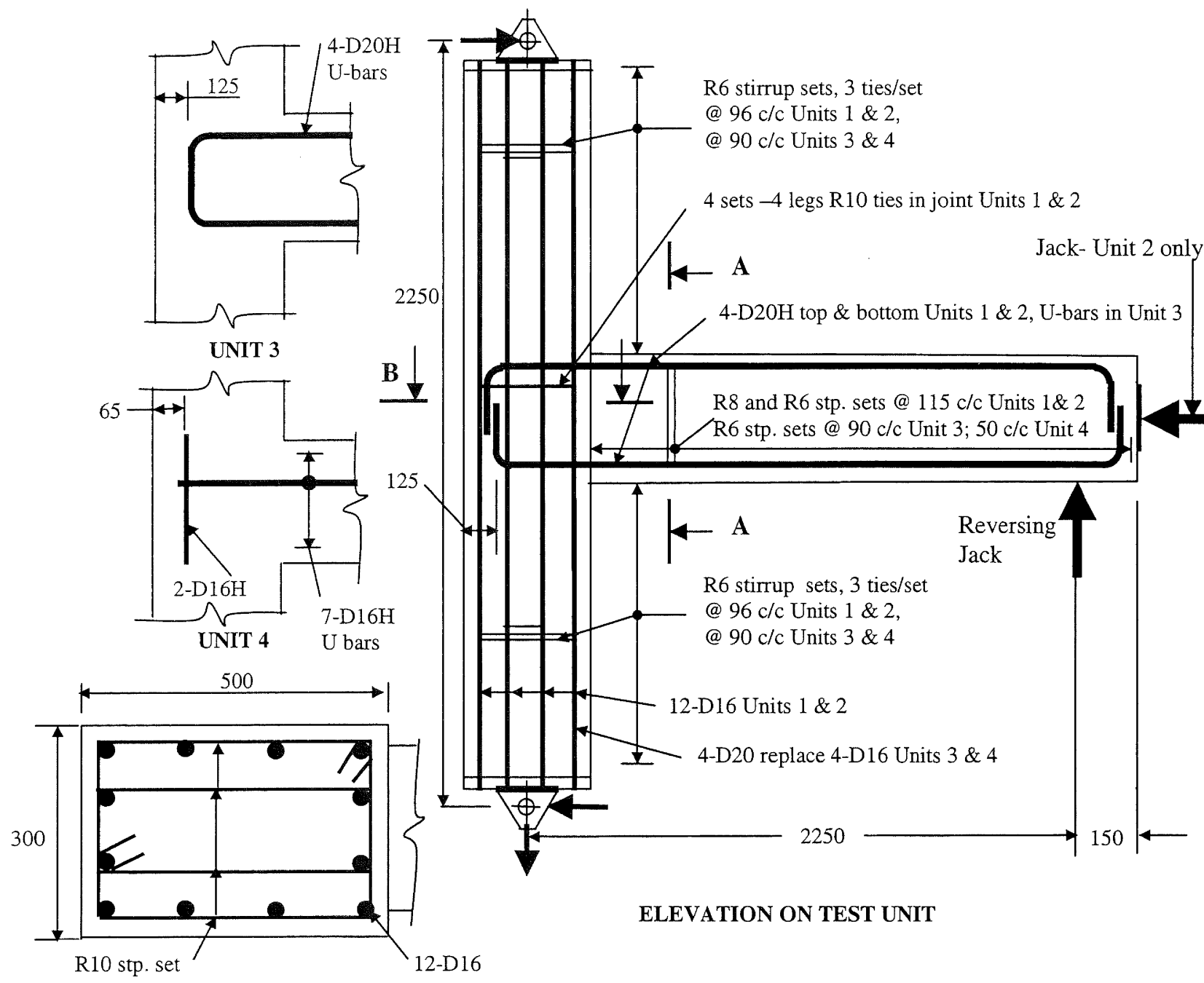

SECTION B-B Units $1 \& 2$

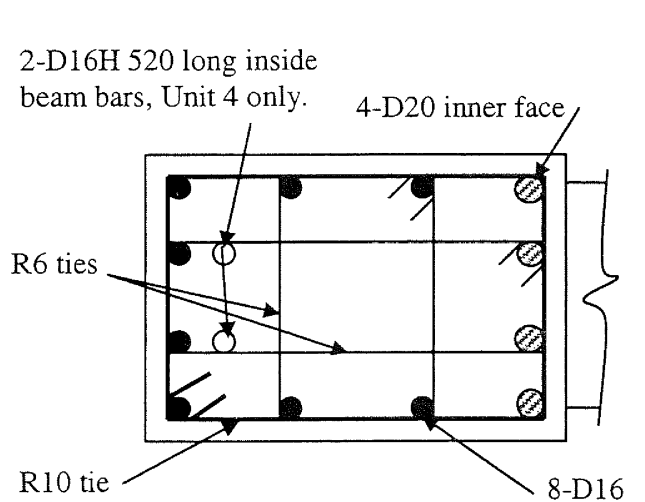

SECTION B-B Units $3 \& 4$
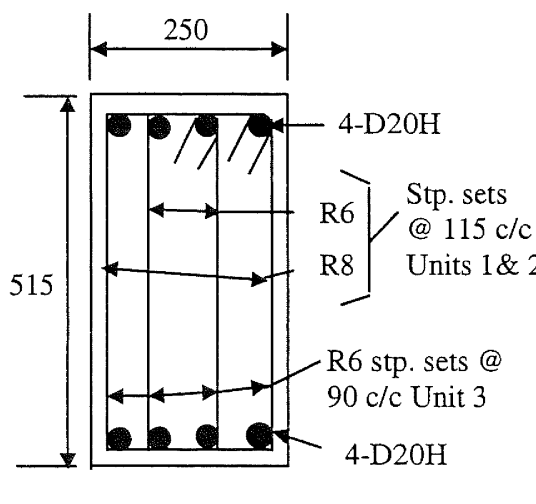

SECTION A-A Units 1, 2 \& 3
7-D16H horizontal U-bars @ $72.5 \mathrm{c} / \mathrm{c}$

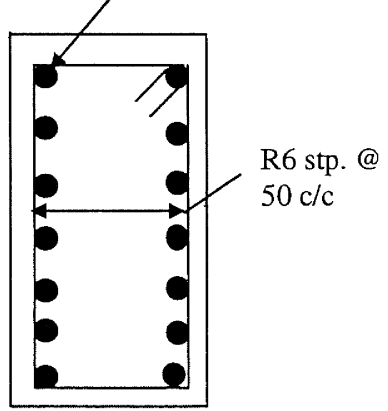

SECTION A-A Unit 4

Figure 1. Details of test units. 


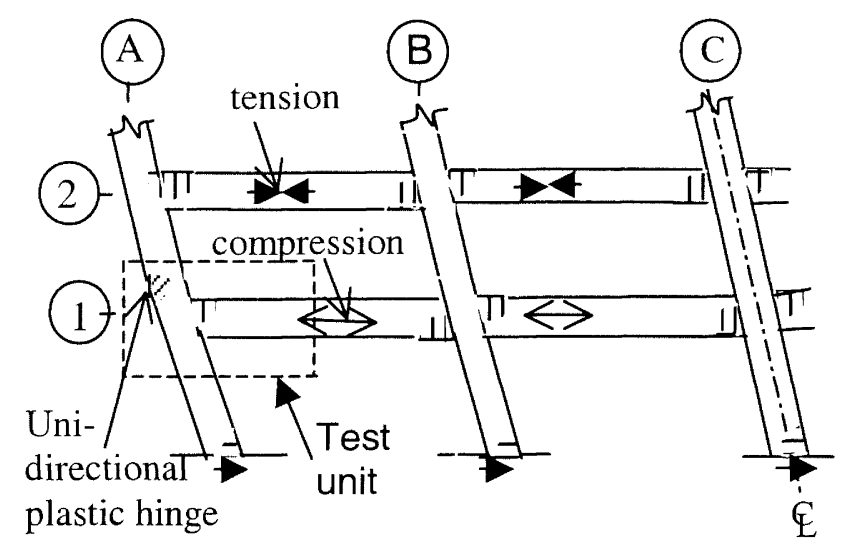

Figure 2. Deformation of column due to elongation

Table 1: Theoretical flexural strengths of beam and column sections.

\begin{tabular}{|c|c|c|c|c|c|c|}
\hline Unit & Beam & \multicolumn{5}{|c|}{ Column $(\mathrm{kNm})$} \\
\hline & $\begin{array}{c}\mathrm{M}_{\mathrm{n}} \\
(\mathrm{kNm})\end{array}$ & $\begin{array}{c}\text { Lower column } \\
\text { under } \\
\text { maximum } \\
\text { axial tension }\end{array}$ & $\begin{array}{c}\text { Lower column } \\
\text { under maximum } \\
\text { axial } \\
\text { compression }\end{array}$ & $\begin{array}{c}\text { Upper column } \\
\text { under dead load, } \\
\text { outside edge in } \\
\text { tension }\end{array}$ & $\begin{array}{c}\text { Upper column } \\
\text { under dead load, } \\
\text { outside edge in } \\
\text { compression }\end{array}$ & $\begin{array}{c}\text { Strength ratio, } \\
\text { beam to } \\
\text { column } \\
\text { strengths }\end{array}$ \\
\hline 1 & 252 & 145 & 202 & 173 & 173 & 1.32 \\
\hline 2 & 252 & 145 & 202 & 173 & 173 & $*$ \\
\hline 3 & 268 & 202 & 206 & 173 & 233 & 1.49 \\
\hline 4 & 270 & 202 & 206 & 173 & 233 & 1.48 \\
\hline
\end{tabular}

* Dependent on beam axial load.

\section{TESTING PROCEDURE}

The first part of the testing was force controlled where the units were loaded to $\pm 3 / 4$ of the force necessary to develop the theoretical flexural strength of the beam at the column face. The peak positive and negative displacements due to deformation in the units were found by subtracting the displacement arising from movement of the column supports. The resulting values were averaged neglecting the sign, and this value was linearly extrapolated to the theoretical strength to give the ductility one displacement. The rest of the test was displacement controlled by imposing two complete reversing cycles to displacement ductilities of $2,4,6$ and in some cases 8 . The load displacement curves shown for the units were corrected for movement of the supports in all cycles.

As previously noted, in unit 2 an axial force was applied to the free end of the beam to prevent any horizontal movement of the jack applying the vertical loading to the beam. Horizontal forces arose due to elongation of the plastic hinge in the beam and the lateral stiffness of the column. This force was adjusted at every load increment to allow for any change in the elongation measured in each increment. The additional moments and shears arising from the change in slope of the jack applying the axial load were included in the results. 


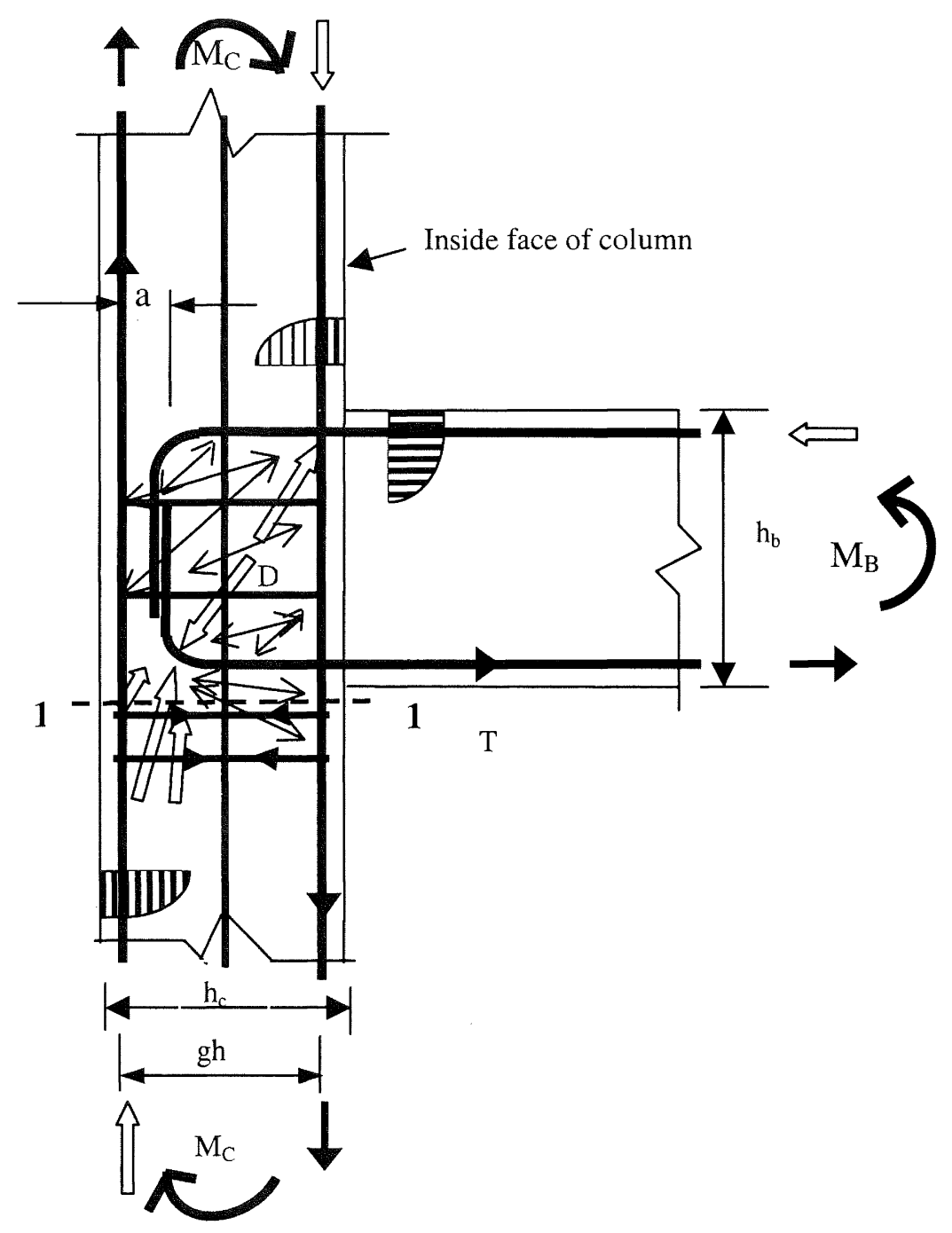

Figure 3. Actions in an external beam-column joint.

\section{TEST RESULTS}

\subsection{Unit 1}

Flexural cracking developed in the beam and the columns together with a number of fine diagonal cracks in the joint zone during the force controlled cycles. The 3 widest cracks were in the beam at the column face and in the joint zone along the top and bottom beam reinforcement. During the displacement controlled load cycles the column face crack steadily increased in width and in the second ductility 6 cycle its width was $18 \mathrm{~mm}$ at the level of the bottom beam reinforcement. This indicated substantial reinforcing slip had occurred. In this cycle the yield penetration into the beam was $300 \mathrm{~mm}$ for the top reinforcement and $140 \mathrm{~mm}$ for the bottom reinforcement. At this stage appreciable spalling had occurred in the joint zone and in the column immediately under the joint zone. There was some loss of strength, which it is believed was associated with this spalling. The maximum principal tensile stress in the joint was $0.56 \sqrt{f}$, with an axial tensile column stress of nearly 1
MPa. This principal tensile stress exceeds the expected limit for exterior columns with beam bars bent inwards of $0.42 \sqrt{f}$, given by Priestley [5] for joint zones without ties. Thus some diagonal cracking was anticipated. Figure 4 shows Unit 1 at the second cycle to ductility 6 with damage to the joint and column and the formation of a column plastic hinge just below the joint.

Mechanical strain gauges on the column reinforcement indicated that extensive yielding occurred in the column bars closest to the inside face of the column. In the ductility 2 cycles the average strains over a $100 \mathrm{~mm}$ gauge length reached about 5.5 yield strains on these bars at the level of the lower beam bars, while during the ductility 4 and 6 cycles these values increased to approximately 12 yield strains. Localised strains could have been appreciably greater than these average values.

The high strains on the inside longitudinal column bars in the locality of the bottom reinforcement in the beam caused wide cracks to form along these bars in the joint zone. This reduced the bond resistance and was responsible for the slip of the reinforcement and the large crack at the face of the 
column. The strains measured on the column bars indicated that this reinforcement yielded prematurely. A strut and tie diagram showing the flow of the forces in the joint zone is shown in Figure 3. It can be seen that anchoring the beam reinforcement short of the column bars reduces the internal level arm of the flexural forces in the column on the underside of the joint zone (section 1-1). The diagonal compression force in the joint zone, " $\mathrm{D}$ ", which balances the compression forces in the beam and upper column, anchors against the tension force, " $T$ ", at the hook in the bottom beam bars. As indicated the compression force in the lower column is forced to deviate in towards the centre of the column to balance the vertical component of the diagonal force, " $\mathrm{D}$ ". This reduces the internal lever-arm resulting in a localised loss of flexural strength. This reduction could be avoided by increasing the amount of longitudinal reinforcement placed on the inside face of the columns. To allow for this effect the four $16 \mathrm{~mm}$ bars placed on the inside face of the columns in units 1 and 2 were replaced with four $20 \mathrm{~mm}$ bars in units 3 and 4 .

The measured strain in the column bars located next to the inside face of the column, immediately under the joint zone, was of the order of 0.02 when the maximum upward load was sustained by the unit. Under this condition the axial tensile load in the lower column was $133 \mathrm{kN}$. This value is equal to the jacking force of $144 \mathrm{kN}$ minus the dead load of the beam and upper column, which was equal to $11 \mathrm{kN}$. Using these two values the theoretical bending moment resisted by the section is found to be $135 \mathrm{kNm}$, which was close to 10 percent greater than the actual bending moment resisted by this section under the action of the maximum measured jacking force. From this it was concluded that this strength loss was due to the reduction of the internal leverarm, which is illustrated in Figure 3. To compensate for this loss in strength the reinforcement can be designed using standard theory for an increased bending moment, $\mathbf{M}_{n}{ }^{\prime}$. The loss in strength is assumed to be proportional to the ratio of the distance between the external column bars and the plane containing the bent up beam reinforcement and the distance between the inside and outside column bars. This ratio is given by "a/gh", where the dimensions a and gh are shown in Figure 3 . In the test of unit 1 the ratio a/gh was equal to 0.22 and the strength loss is 10 percent. Hence the value of $\mathrm{M}_{\mathrm{n}}{ }^{\prime}$ is given by-

$$
\mathrm{M}_{\mathrm{n}}{ }^{\prime}=\mathrm{M}_{\mathrm{n}}(1+0.46 \mathrm{a} / \mathrm{gh})
$$

Using standard theory and the $\mathrm{M}_{\mathbf{n}}{ }^{\prime}$ value should give a flexural strength of $M_{n}$. This is achieved by increasing the area of the longitudinal reinforcing bars located adjacent to the inside face of the column.

Figure 6 , for unit 1 , shows the force applied to the beam versus the displacement of the beam at the load point. The strength degraded more rapidly for the upward loaded half cycles than when the loading was downwards. Yielding in the joint tie legs only occurred in the top leg of the outer joint tie during the second ductility 4 cycle. However in that cycle all tie legs had recorded strains exceeding $60 \%$ of the yield strain, measured at the column centreline, with the outer tie legs having higher strains than the corresponding inner legs.

\subsection{Unit 2}

The pre-yielding cyclic behaviour of Unit 2 was similar to the first unit but the inelastic displacement cycles showed marked differences. Figure 10 shows how the elongation in the beam increased steadily with the ductility level to reach a value of $16 \mathrm{~mm}$ (close to $3 \%$ of the beam depth) at the end of the test. The beam axial force ranged between 110 and 210 $\mathrm{kN}$, but it averaged close to $150 \mathrm{kN}$. It was typically $25 \mathrm{kN}$ higher for downward loading than for upward loading.

The beam elongation pushed the column outwards and this was associated with extensive yielding of the longitudinal column bars placed close to the outside column face. In the ductility 4 cycles this reached 12 yield strains and in the ductility 6 and 8 cycles it was of the order of 18 yield strains. The bending of the column due to beam elongation induced compression, or reduced the tension forces, on the reinforcement on the inside face of the column. As a result the bond conditions for the beam bars were very much better than in unit 1. This was reflected in greater length of yielding reinforcement in the beam in unit 2 when compared with unit 1 , and a greatly reduced crack width in the beam at the face of the column. The tensile curvatures reached in the beam between 60 and $495 \mathrm{~mm}$ (d) out from the column face were over twice those reached in Unit 1 . The damage is shown in Figure 5 at the second cycle during testing to ductility 6 .

In this test substantial inelastic deformation developed in the joint zone and spalling occurred in this region during the ductility 6 and 8 cycles, which led to the loss of strength. All the joint ties yielded in this unit by or during the ductility 6 cycles, with the mid-joint ties reaching strains of about 5 yield strains.

Figure 7 , which is for unit 2 , shows the force applied to the beam versus the displacement of the load point. It can be seen that the strength was greater than for unit 1 . This increase arose from the action of the axial load on the beam. At a value of $150 \mathrm{kN}$ this gives an increase in beam flexural strength of close to $32 \mathrm{kNm}$. Strength degradation did not occur until the ductility 8 cycles. The enhanced strength of this unit arises from 2 factors, namely;

- The axial compressive force increased the beam's flexural strength;

- The axial force in the beam suppressed the flexural tensile forces on the inside of the column adjacent to the beam. This prevented the structural performance of the joint zone being reduced by bond degradation of the beam reinforcement in the joint zone.

Analysis of the results indicates that the axial force, arising from elongation of the beam, was a function of the flexural strength of the column. For downward loading, with an axial force of $200 \mathrm{kN}$ acting horizontally on the beam and the theoretical flexural strength of the beam acting at the column face, a bending moment of $201 \mathrm{kNm}$ is induced in the column on the lower face of the joint zone. This can be compared with the theoretical section strength of the column of $202 \mathrm{kNm}$ (see Table 1). With upward loading the flexural strength is reduced due to the drop in the column axial force in the critical section, which with this direction of loading is now located immediately above the joint zone. Hence the observed decrease in beam axial force for upward loading. 


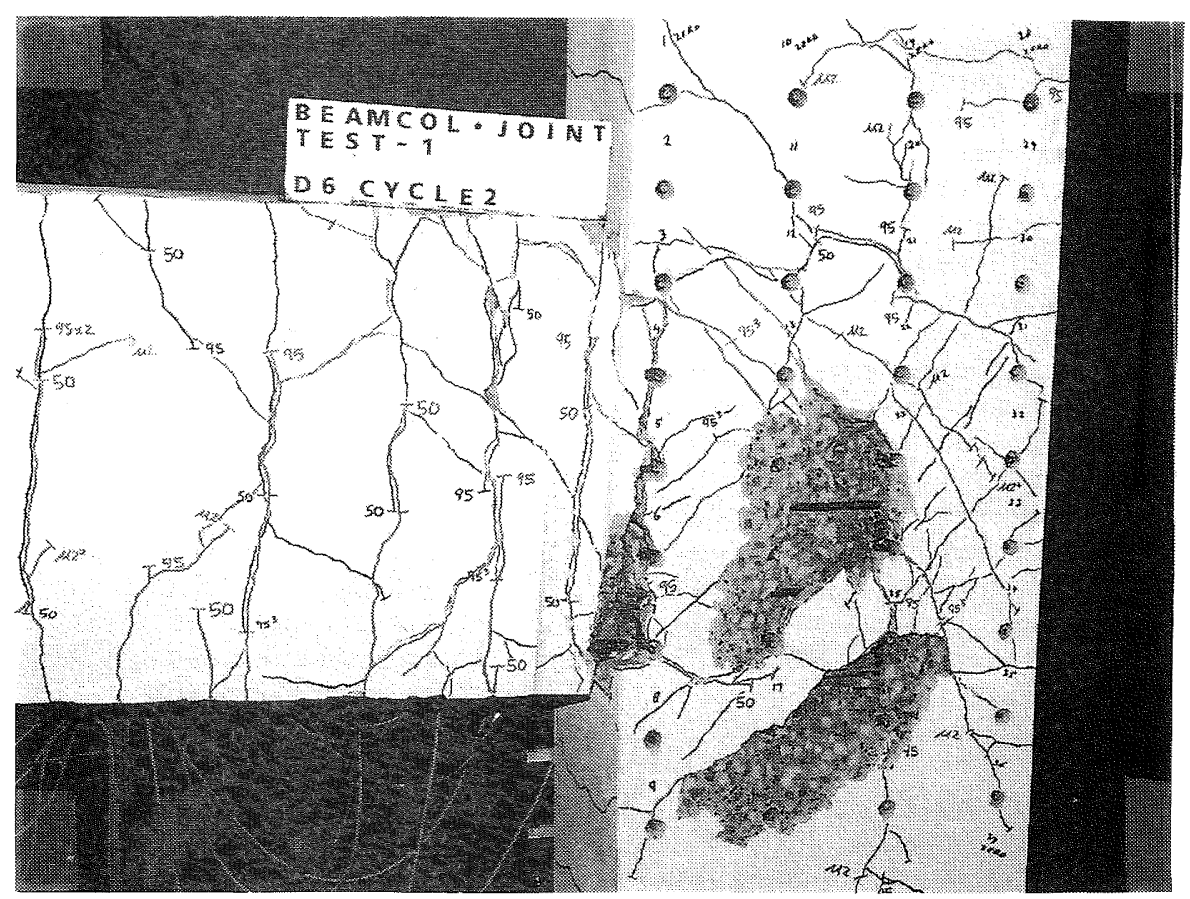

Figure 4. Unit 1 in the second cycle to ductility 6 showing damage to the joint and lower column.

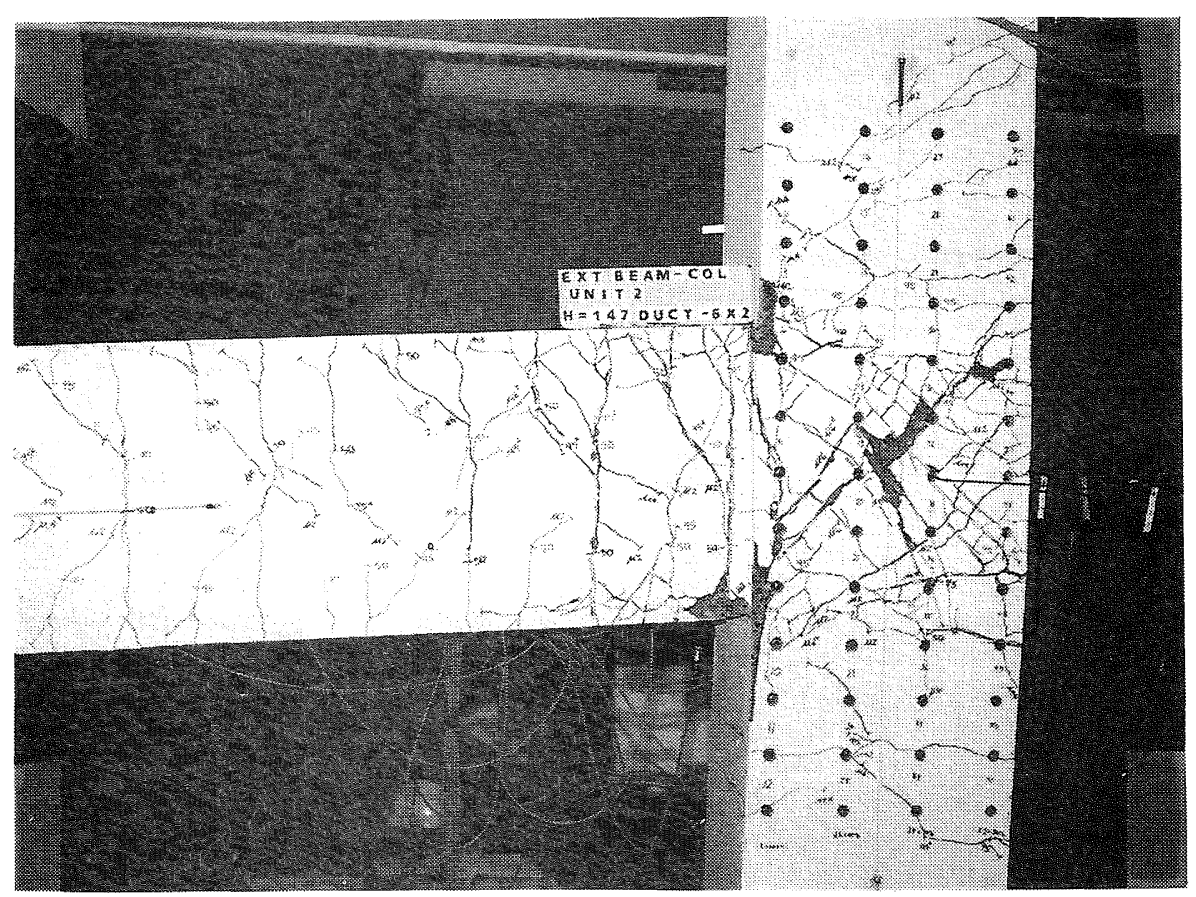

Figure 5. Unit 2 at ductility 6 in the second cycle. Note the column plastic hinge forming below the joint. 


\subsection{Unit 3}

The jacking force applied to the beam versus beam displacement relationship is shown in Figure 8 . Good ductile energy absorbing behaviour occurred up to the second cycle at ductility 6 , where strength degradation occurred. There was a slight decrease in sustained force in the downward direction between cycle peaks at ductilities 4 and 6 . The column face crack widened steadily during the test while the majority of the deformation was due to beam flexure. As the test progressed the proportion of the beam deflection due to joint shear increased, while the beam flexural deformations remained about constant from the ductility 4 cycles on. This implied some loss in strength occurred in the joint zone and plastic hinge zone of the beam.

Unit 3 had the larger D20 bars on the column's inner face in an attempt to overcome the local reduction in column flexural strength at the joint zone that was observed in unit 1 . The mechanical strain gauges indicated that only very limited yielding, if any, occurred on the column bars during this test.

\subsection{Unit 4}

The ductility 1 deflection in this unit was greater than in the previous three units. This is in part due to the uniform distribution of longitudinal reinforcement in the beam, which reduced the section stiffness, based on the cracked section, by close to 15 percent. The theoretical flexural strength was almost identical to that of unit 3 . The jacking force applied to the beam versus displacement relationship is shown in Figure 9. The theoretical over-strength force $(151 \mathrm{kN})$ to reach the beam section's theoretical over-strength moment was reached in the first upward ductility 2, 4 and 6 cycles and in the first downward ductility 4 cycle. In the second ductility 6 cycle the jacking force decreased to about $50-60 \%$ of that corresponding to the beam's over-strength moment due to the extensive spalling in the plastic hinge zone and buckling of the reinforcement.

The beam flexural component of the total beam deflection was the largest contribution, although the beam shear and joint shear components steadily increased at each successive inelastic cycle. However the beam and joint shear component of the deflection was only about half of that measured in unit 3 .

\subsection{Elongation in Units}

The elongation of the beams measured in the four units is shown in Figure 10. It can be see that the peak values range from 8 to $16.5 \mathrm{~mm}$. The greatest value was in unit 2 where an axial restraining force acted on the beam! The lowest value was for the upward loading in unit 1 , where extensive slip of the bottom beam bars prevented appreciable yield penetration into the beam. A consequence of this is reduced elongation. The next lowest values were in unit 4 , which contained longitudinal reinforcement spread over the depth of the beam. In this case the area of reinforcement in tension exceeded that in compression, and as a result the compression reinforcement tended to yield back in compression to a limited extent, which reduced elongation.
From these tests it can be seen that, with the exception of upward loading in unit 1 , at the design level of ductility for ductile structures the elongation in each plastic hinge zone lay between 2 and $2.8 \%$ of the beam depth.

\section{CONCLUSIONS}

1 Anchoring the beam bars in external beam column joints short of the outside column bars locally reduces the flexural strength of the column at the face of the joint zone when the inside bars are subjected to tension. In the first unit, where the bottom beam bars were anchored at a depth of $3 / 4$ of the depth of the column from the inside face, (as permitted by the NZ Concrete Standard 3101) the reduction in flexural strength resulted in extensive yielding of the inside bars. The cracking associated with this yielding led to the formation of wide cracks along the bottom beam bars in the joint zone and this reduced bond resistance and adversely affected the performance of the joint zone.

2 The adverse effects described in 1 above can be overcome by increasing the area of longitudinal column reinforcement placed on the inside face of the column. A simple expression is given for an enhanced design strength for the column to compensate for this loss in strength.

3 In all the tests the plastic hinge zone in the beam elongated by close to $3 \%$ of the beam depth at design ductility levels. In multi-story moment resisting frames this elongation induces a unidirectional plastic hinge in the external columns at the level of the first floor. The elongation of the beam did not adversely affect the performance of the joint zone in this test. However, the same conclusion may not hold where a high axial load acts on the column.

4 Detailing the anchorage of the longitudinal beam reinforcement in the joint zone by bending the top bars in a $U$ shape, so that they are continuous with the bottom bars, was found to improve the performance compared with that obtained when the bars were individually anchored using standard $90^{\circ}$ hooks.

5 The performance of the unit with the beam reinforcement distributed over the depth of the beam was similar to that obtained with the unit with conventional placing of beam bars. The main change was in the reduction of stiffness of the beam associated with the distributed steel. This resulted in the unit having to sustain greater displacements to reach the nominated ductility values.

6 The joint zone ties did not appear to be over strained in these tests. This observation supports the reduction in the area of joint zone ties that is required in the 1995 edition of the concrete Standard as compared to the 1982 edition. 


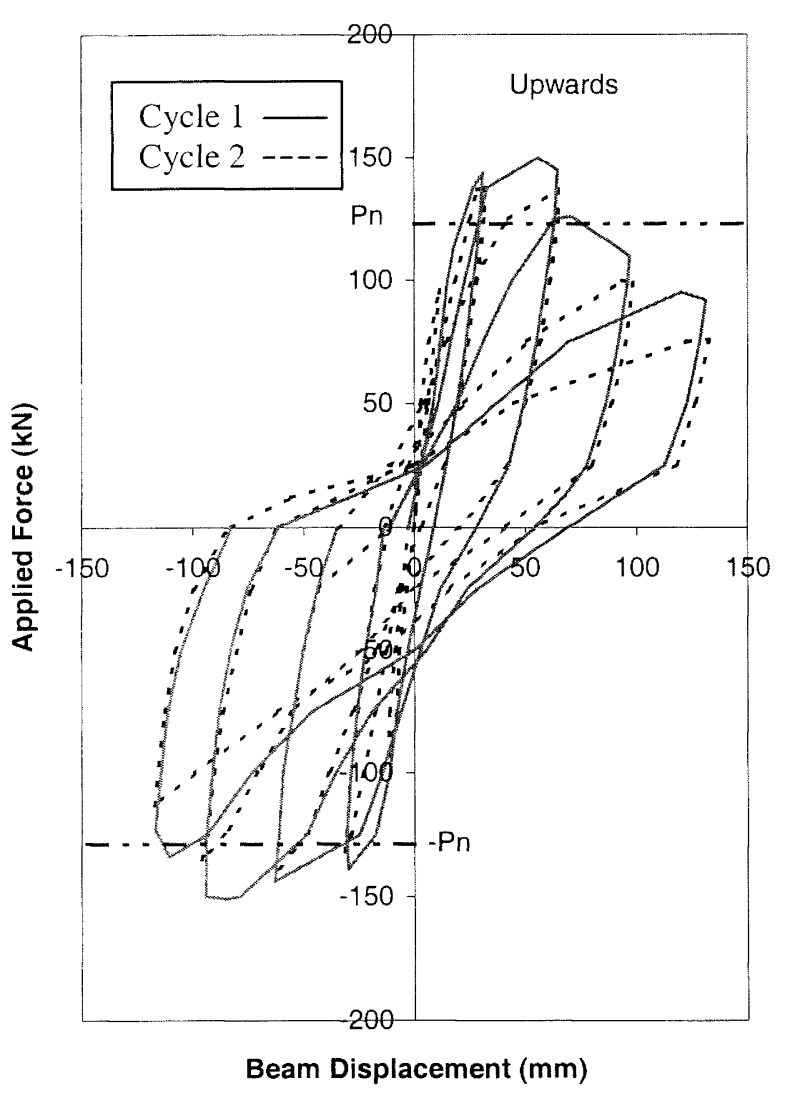

Figure 6. Unit 1

Force-Displacement loops

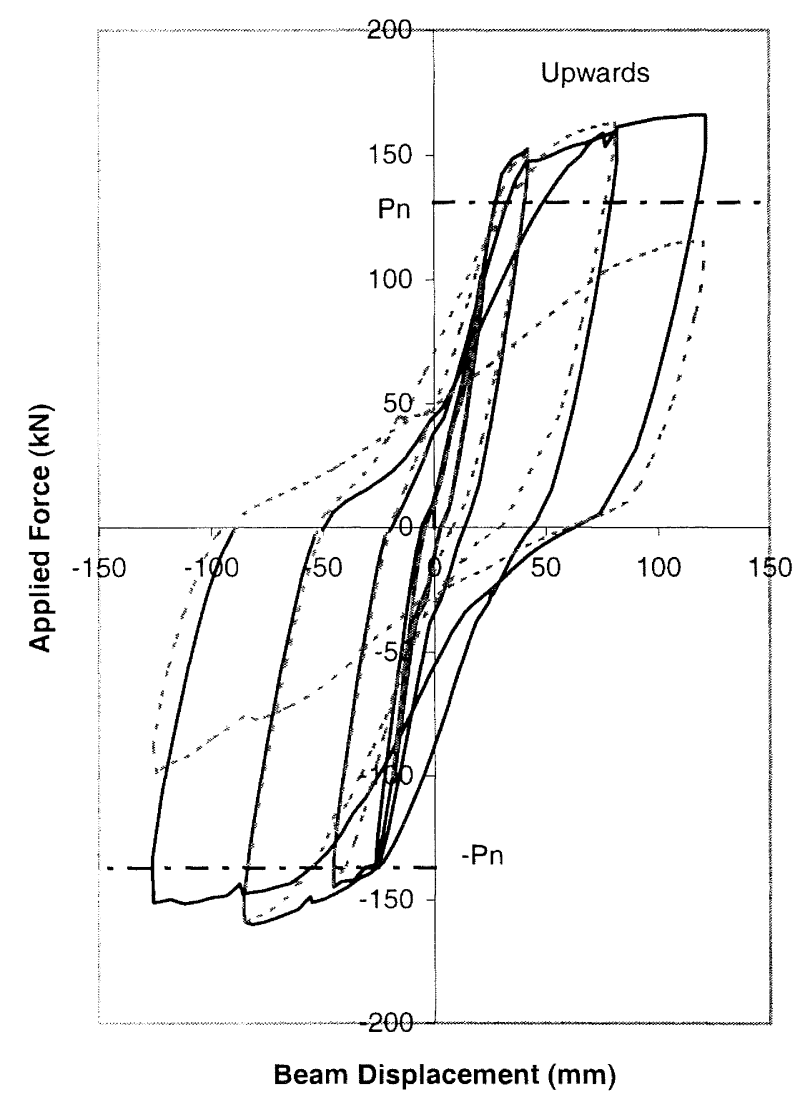

Figure 8. Unit 3

Force-Displacement loops

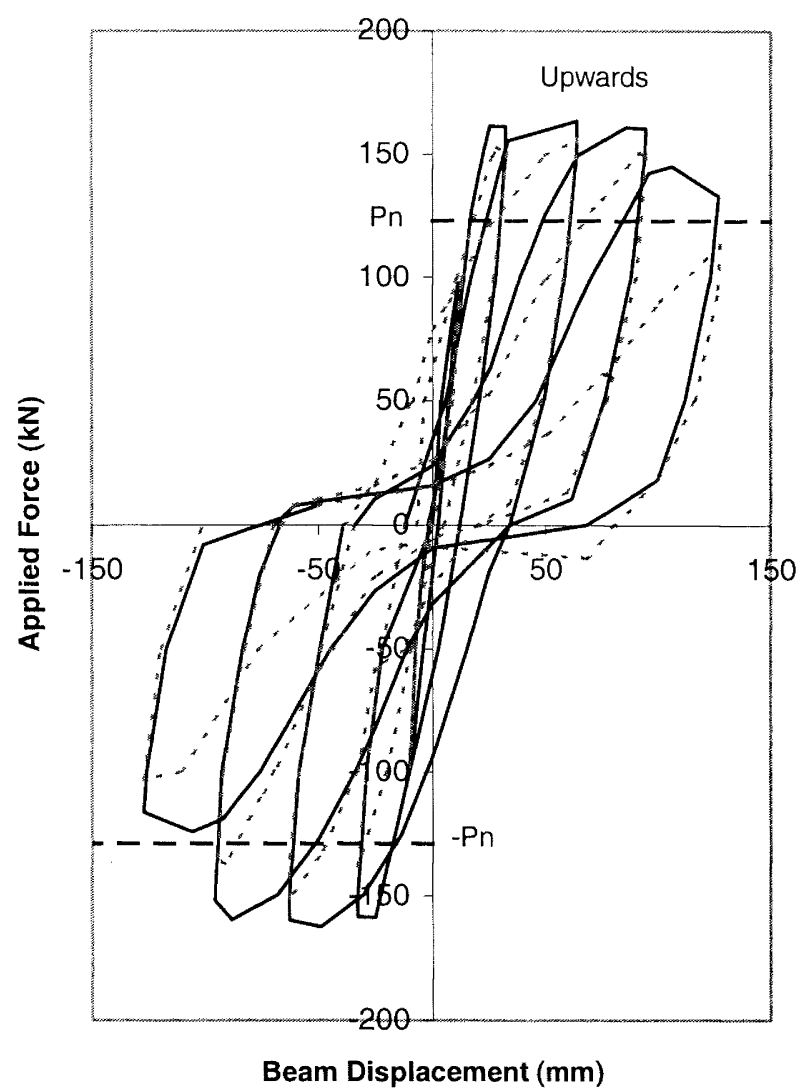

Figure 7. Unit 2

Force-Displacement loops.

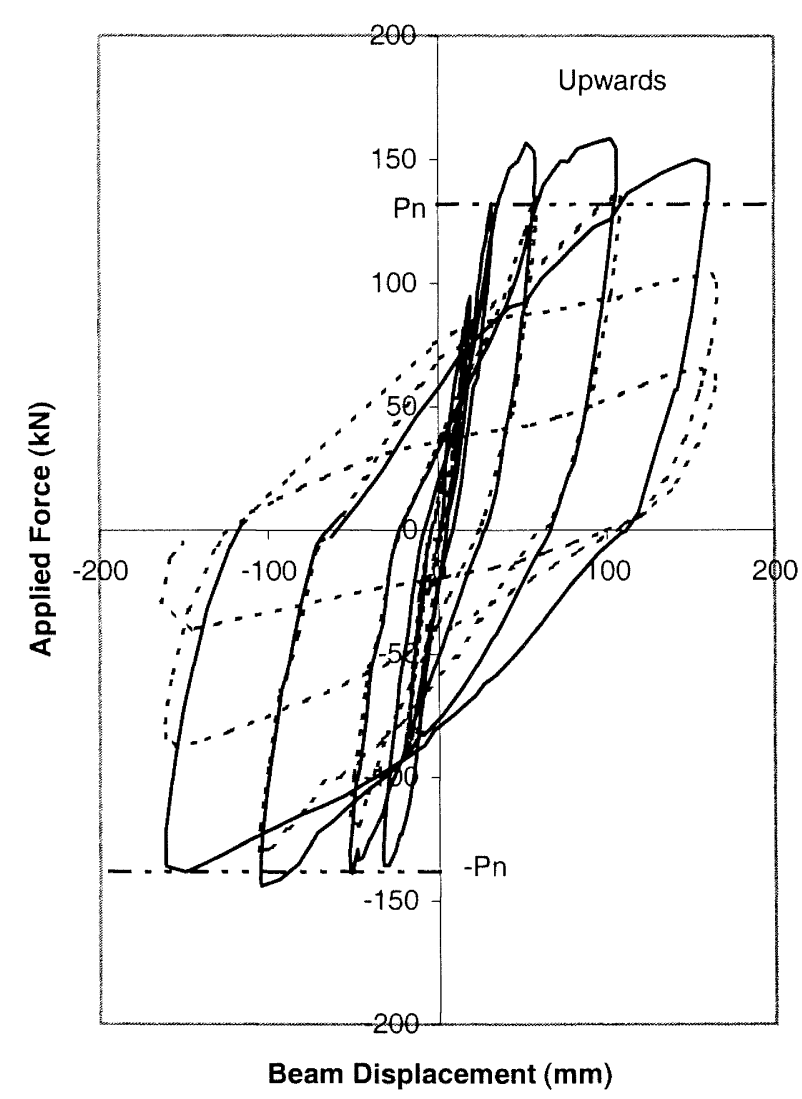

Figure 9. Unit 4

Force-Displacement loops 


\section{ACKNOWLEDGEMENTS}

The tests reported here were partially sponsored by a NZ Earthquake Commission Research Grant and the authors gratefully acknowledge postgraduate students Henao Badira and Utsuhiro Kohno, who tested the units in the Civil \& Environmental Engineering Department's Test Hall at The University of Auckland.

\section{REFERENCES}

1. SNZ (1995), Concrete Structures Standard, Design of Concrete Structures, NZS3101-1995, Standards New Zealand.

2. Fenwick, R.C. and Megget, L.M. (1993), "Elongation and Load Deflection Characteristics of Reinforced
Concrete Members containing Plastic Hinges", NZNSEE Bulletin, 26 (1), pp. 28-41.

3. Fenwick, R.C., Ingham, J.M. and Wuu, P.J.Y. (1996), "The performance of Ductile Reinforced Concrete frames Under Seismic loading", Proceedings NZNSEE Technical Conference, New Plymouth, March, pp. 20-26.

4. Fenwick, R.C. and Davidson, B.J. (1993), "Elongation in ductile seismic resistance reinforced concrete frames", Paulay Symposium, ACI Special publication SP-157 1993, pp. $141-168$

5. Priestley, M.J.N. (1996), "Displacement-based Seismic Assessment of Existing Reinforced Concrete Buildings", NZNSEE Bulletin, 29 (4), pp. 256-272.

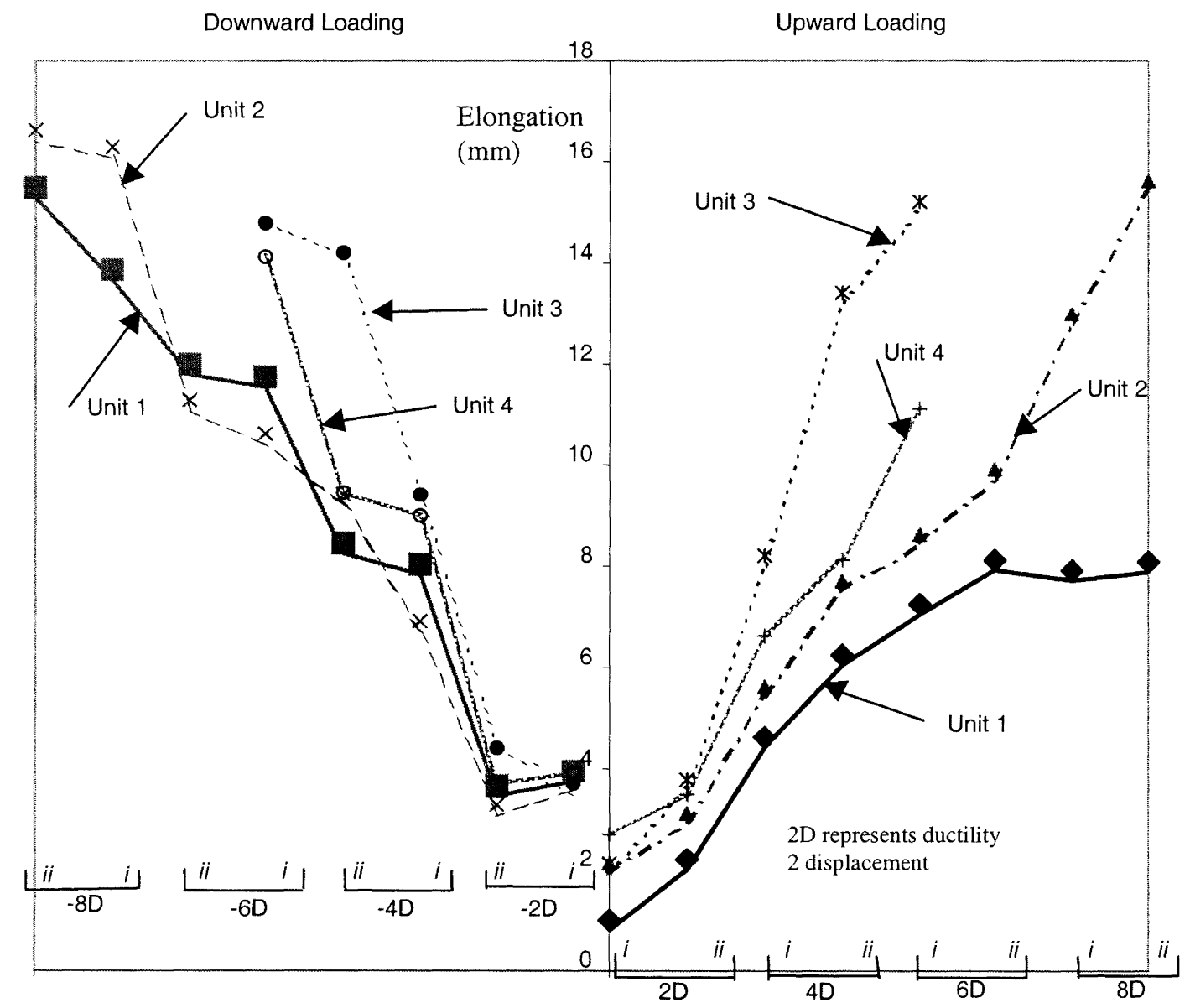

Figure 10. Beam Elongation for Beam-Column units 1-4 